\title{
Bone marrow cell-mediated production of transgenic chickens
}

\author{
Young Tae Heo ${ }^{1}$, Sung Ho Lee ${ }^{1}$, Ji Hoon Yang ${ }^{1}$, Teoan Kim² and Hoon Taek Lee ${ }^{1}$
}

The transplantation of adult stem cells into recipients is a method used widely in mammals to determine the fate of transferred cells, and for the production of progenies. This study is the first report, to our knowledge, to demonstrate the successful production of chickens using cells transdifferentiated from adult chicken bone marrow cells (BMCs) transplanted into the testes. BMCs from the enhanced green fluorescent protein (eGFP) transgenic (Tg) chickens were induced via in vitro transdifferentiation to male germ cells and injected into the testes of normal recipients. The multipotency of BMC was found with RT-PCR, immunocytochemistry, and FACS using specific markers, such as OCT4 and SSEA-1, -3 , and -4. Localization and in vivo transdifferentiation of injected cells in the seminiferous tubules of recipients were traced for up to 40 days' post-injection by GFP expression and immunocytochemical analyses. The integration of the eGFP and the $n e o^{R}$ genes in sperm gDNAs of recipient was confirmed via PCR analysis. A subsequent testcross of the recipient roosters with non-Tg hens resulted in the production of eGFP Tg progenies, demonstrating the successful transdifferentiation of the adult BMC to the germ cells in the testis. Therefore, we suggest that the use of adult BMCs is a new and promising approach to the production of Tg poultry, and may prove helpful in the study of avian developmental biology. Laboratory Investigation (2011) 91, 1229-1240; doi:10.1038/labinvest.2011.53; published online 25 April 2011

KEYWORDS: bone marrow cell; green fluorescent protein (GFP); transdifferentiation; transgenic chicken

Avian species are generally thought to be an ideal model for developmental biology and bioreactor systems targeted toward the efficient production of therapeutic proteins from animals. The advantages of avian models for these studies generally involve certain of their physiological features, including short generation time, fecundity, and abundant protein content in the egg. ${ }^{1}$ Several methods have been developed to study transgenesis in avians, including the use of primordial germ cells, blastodermal cells, or testicular cells. ${ }^{2-4}$ However, it is notoriously difficult to control differentiation in these cells in long-term culture systems. As a result, the success rate of these approaches remains fairly low. ${ }^{5}$ Although adult stem cell research in mammals is well developed and has progressed a great deal, few studies thus far have addressed adult stem cell research in avians.

Until recently, the fate of adult stem cells was believed to differentiate only into the tissue or organ from which they originated. However, over the past few years, it has been demonstrated that several adult stem cells may undergo unexpected fates under specific physiological conditions.
One of the best examples of this is bone marrow cells (BMCs) consisting of various types of cells, such as endothelial stem cells (ESCs), mesenchymal stem cells, and unknown multipotential adult progenitor cells. ${ }^{6}$ Isolated stem cells from bone marrow have previously been shown to transdifferentiate into blood cells, hepatocytes, skeletal muscle, neural cells, and cardiomyocytes. ${ }^{7-11}$ Interestingly, recent studies have demonstrated that BMC transdifferentiates into female as well as male germ cells. ${ }^{12-16}$ In avians, however, no studies have been conducted thus far regarding bone marrow stem cells.

In this study, we hypothesized that cells derived from bone marrow can transdifferentiate into male germ cells in chicken. To evaluate this hypothesis, we attempted to induce BMC via in vitro transdifferentiation into male germ cells, to trace the fate of the transferred BMC in the seminiferous tubules of the testes and to produce progeny chicks using the sperm of recipient roosters injected into the testes with BMC. Our results describe another unique transgenic (Tg) production system, and contribute to our current understanding of avian adult stem cells in bone marrow.

\footnotetext{
'Department of Bioscience and Biotechnology, Bio-Organ Research Center, ARRC, Konkuk University, Seoul, Korea and ${ }^{2}$ Department of Physiology, Catholic University of Daegu School of Medicine, Daegu, Korea

Correspondence: Professor HT Lee, PhD, Department of Bioscience and Biotechnology, Konkuk University, Bio-Organ Research Center, ARRC, 1 Hwayang-dong, Gwangin-gu, Seoul 143-701, Republic of Korea.

E-mail: ht13675@konkuk.ac.kr

Received 11 June 2010; revised 26 October 2010; accepted 8 November 2010
} 


\section{MATERIALS AND METHODS Experimental Animals}

One adult (35 weeks of age) Barred Plymouth Rock was used for the characterization of BMC, and one adult (28 weeks of age) and one prepubertal (16 weeks of age) enhanced green fluorescent protein (eGFP) $\mathrm{Tg}$ roosters ${ }^{17,18}$ were used as donors for the transfer of BMC into the recipients' testes. The recipient roosters included 13 White Leghorn at prepubertal and adult stage. Four of the 13 recipients were sequentially killed for the tracing of eGFP bone marrow donor cells in the recipients' seminiferous tubules, and others are used for testcrosses. Animal management, reproduction, and surgical procedures were conducted in accordance with the legal requirements established by Konkuk University.

\section{Isolation and Culture of BMCs}

Chicken BMCs were collected by flushing the femurs and tibias from eGFP Tg roosters with Dulbecco's phosphatebuffered saline (PBS) (Gibco). After filtering the cells through a $70-\mu \mathrm{m}$ nylon mesh filter, the cells were loaded on a threelayered density gradient $(0,45,90 \%)$ of Percoll and centrifuged. The selected cell population was dissociated via trypsin-EDTA treatment, and $\sim 1 \times 10^{6}$ cells were placed in $60 \mathrm{~mm}$ dishes with DMEM/F12 supplemented with $10 \% \mathrm{FBS}$, $0.5 \mathrm{mM} \beta$-mercaptoethanol, $20 \mathrm{ng} / \mathrm{ml}$ basic fibroblast growth factor (bFGF; ESG1106 Chemicon), 1000 unit $/ \mathrm{ml}$ human leukemia inhibitory factor (LIF; 13256, Invitrogen). For immunocytochemistry, $2 \times 10^{4}$ cells were seeded onto $60 \mathrm{~mm}$ $0.1 \%$ gelatin-coated well plates. The seeded cells were cultured in an incubator at $36.5^{\circ} \mathrm{C}$ and $5 \% \mathrm{CO}_{2}$ at a relative humidity of $60 \%$. For retinoic acid (RA) treatment, the collected BMCs were placed in $60 \mathrm{~mm}$ non-coated dishes with DMEM/F12 supplemented with $10 \%$ knockout serum supplement, $0.5 \mathrm{mM} \beta$-mercaptoethanol, $20 \mathrm{ng} / \mathrm{ml}$ of bFGF, and $1000 \mathrm{unit} / \mathrm{ml}$ of LIF for 1 day in order to induce sphere formation, after which the knockout serum was replaced with FBS. Cultures were maintained in the above medium for an additional 2 weeks, and the medium was exchanged with the above medium containing $10^{-6} \mathrm{M}$ of RA (Sigma) for 10 days.

\section{Transplantation of BMC and Testcross Analysis}

We administered busulfan (Sigma), a chemotherapeutic agent that destroys proliferating cells, to recipient roosters in order to eliminate spermatogenesis; therefore, it facilitates the localization and competition of donor BMCs. ${ }^{19}$ In our study, recipient normal roosters 16 and 40 weeks of age were treated twice with busulfan $(40 \mathrm{mg} / \mathrm{kg}$ body weight $)$ at 2 week intervals. Two weeks after the final busulfan treatment, isolated and cultured BMC $\left(3 \times 10^{8}\right.$ in $\left.1 \mathrm{ml}\right)$ were surgically transferred into the testes of each recipient after anesthetizing with $0.1 \mathrm{ml} / \mathrm{kg}$ of Zoletil 50 (Virbac Laboratories, Carros, France). In brief, the abdominal cavity was opened $\sim 2 \mathrm{~cm}$ on each side just behind the last rib, and $1 \mathrm{ml}$ of BMC suspension $\left(3 \times 10^{8} / \mathrm{ml}\right)$ was injected directly into the testes using an insulin syringe (31 gauge, BD, Holdrege, USA). At 10 weeks, spermatogenesis was complete; after BMC transplantation, samples of ejaculated semen from four recipient roosters were collected twice a week using the conventional abdominal massage technique and utilized for the artificial insemination of normal hens. ${ }^{20}$

\section{Immunocytochemistry and Cell Surface Phenotype}

For immunocytochemistry, cultured cells, sliced testis tissues and smeared semen on slides were fixed with $4 \%$ paraformaldehyde in $0.1 \mathrm{M}$ PBS, then permeabilized for $10 \mathrm{~min}$ with $0.2 \%$ Triton X-100. After washing with PBS, the cells and sperm were incubated for $1 \mathrm{~h}$ with $10 \%$ normal goat serum to block any non-specific binding, then incubated overnight with primary antibody at $4^{\circ} \mathrm{C}$. After washing with PBS, the cells were then incubated with secondary antibody for $1 \mathrm{~h}$ and the nuclei were counterstained with DAPI (1:2000; Sigma). The primary antibodies used were monoclonal antibodies against SSEA-1 and SSEA-3 (1:50; Santa Cruz, Biotechnology, Santa Cruz, CA, USA) and polyclonal antibodies against Oct-4 (1:250; Santa Cruz Biotechnology), Vasa, C-kit, Dazl, and GFP (1:100; Abcam, Cambridge, UK). The secondary antibodies used herein were goat anti-rabbit tetramethyl rhodamine isothiocyanate (TRITC; 1:200; Jackson Laboratories, West Grove, PA, USA) and goat anti-mouse TRITC (1:200; Jackson Laboratories). At least 200 spermatozoa were counted in 20 microscopic fields selected at random. Counterstained spermatozoa showing a green color at the head region were counted as eGFP positive. Spermatozoa that did not react with the antibody against GFP had no green precipitates and appeared blue throughout due to counterstaining and were counted as eGFP negative.

For cell surface phenotype analysis, BMC from eGFP Tg roosters were stained with stem cell surface marker SSEA-4 monoclonal antibodies conjugated with fluorescein isothiocyanate and analyzed via flow cytometry (FACS) with Cellquest software.

\section{PCR and RT-PCR Analysis}

Genomic DNA from ejaculated sperm was isolated using a Blood and Cell Culture DNA Mini Kit (Qiagen, USA). Total RNAs from each layered cell population and cultured cells were isolated with an RNeasy mini kit (Qiagen). Using Accupower RTpremix (Bioneer, CA, USA) and oligo dT-primers (Bioneer) in accordance with the manufacturer's instructions, $0.5 \mu \mathrm{g}$ of total RNA was reverse transcribed into cDNA. PCR was conducted for 30 cycles in a $20-\mu \mathrm{l}$ reaction volume using Accupower PCR premix (Bioneer). The primers utilized for PCR and RT-PCR are listed in Table 1.

\section{Molecular Cloning, Sequencing, and Data Analyses}

Previous research revealed that insertion of provirus in reverse orientation between the nucleotides of 55890-55891 on chromosome $26 .{ }^{17}$ Based on this result, cf primers are designed and PCR amplifications of flanking regions of the provirus were performed. PCR products by cf primers were 
Table 1 Primers used for the RT-PCR and PCR analysis of chBMC and sperm genomic DNA

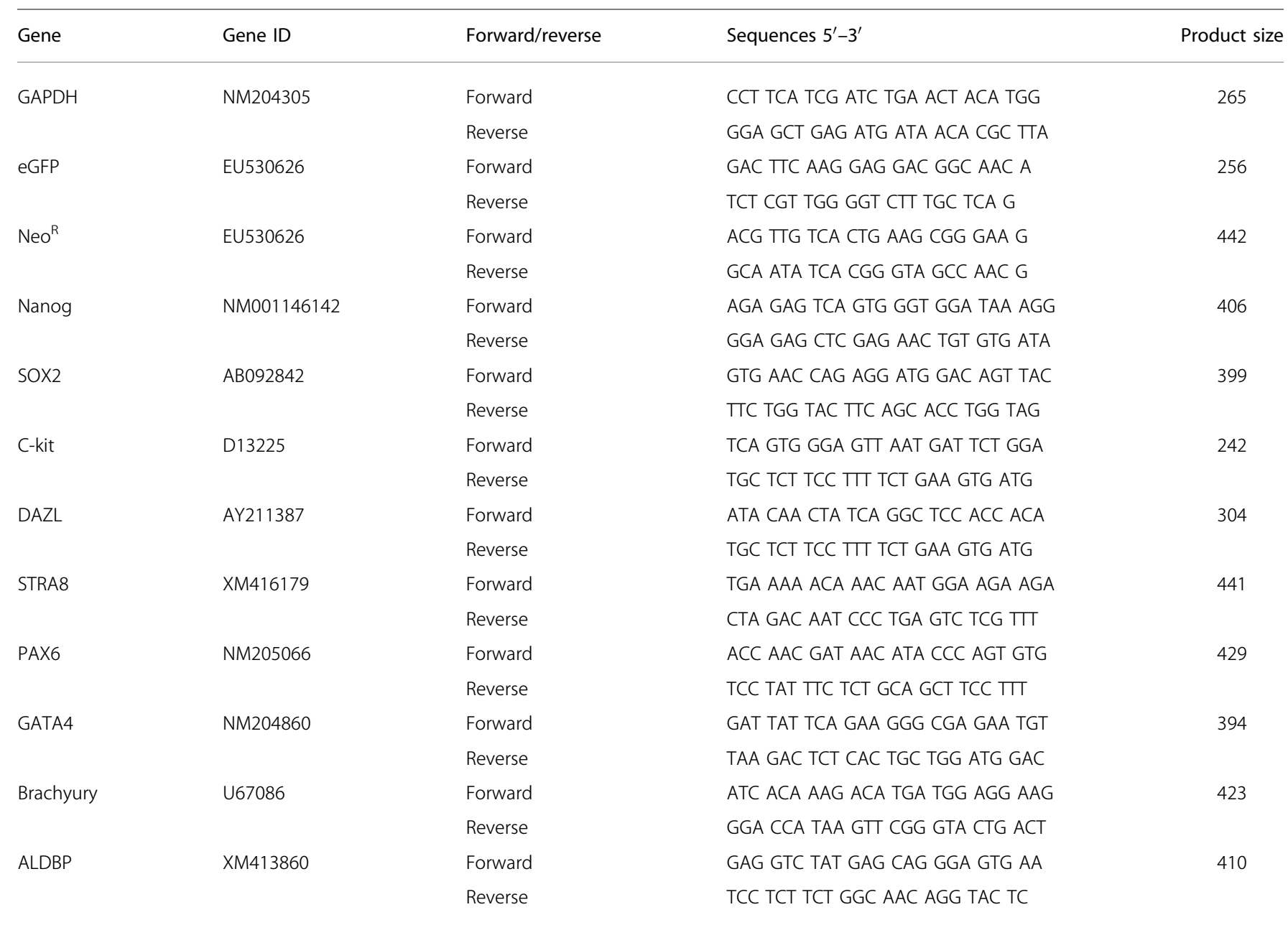

cloned using the pPCR-Script ${ }^{\mathrm{TM}}$ blunt-end cloning kit (Stratagene). The ligated DNA was transformed into DH5 $\alpha$ cells using the heat shock method (MicroPulser ${ }^{\mathrm{TM}}$, Biored). The plasmids were isolated using the Wizard miniprep kit (Promega) based on the manufacturer's instruction. Sequencing reactions were performed using the ABI PRISM BigDye ${ }^{\mathrm{TM}}$ v3.1 terminator sequencing kit (Applied Biosystem) and the products were analyzed on an Applied Biosystem DNA Analyzer (3730, Applied Biosystem). Complete gDNA sequences of the gene were assembled by overlapping forward and reverse sequences. The full-length sequences were aligned using ClustalW. ${ }^{21}$

\section{RESULTS}

After Percoll density gradient centrifugation, the chBMCs were divided into three clear layers of cell population. The RT-PCR results showed that the upper-layer cell population expressed adipocyte lipid droplet-binding protein (ALDBP) and, morphologically, was identified as fat (Figure 1a). The bottom layer was filled largely with red blood cells expressing mesoderm-originated marker (brachyury). By way of con- trast, stem cell-specific markers such as Nanog and Sox2 were expressed from the cells in the middle layer. Consequently, Percoll density gradient centrifugation eliminated fat and red blood cells in bone marrow and helped to isolate multipotent cells for subsequent procedures. The middle-layered cells cultured in DMEM/F12 media without supplementation of cytokines or growth factors for five passages did not express stem cell-specific markers, but did express all three germlayer-specific genes. When fresh chBMC was cultured for 10 days with LIF and bFGF supplements and sequentially cultured for 20 days without LIF and bFGF, the chBMCs were reacted with three germ-layer-specific antibodies (ectoderm: Tuj1, mesoderm: Brachury, endoderm: $\alpha$-fetoprotein) (Figure $1 \mathrm{~b}$ ).

The results of immunocytochemical studies showed partially positive reactions with mammalian stem cell-specific markers such as Oct-4, SSEA-1 and SSEA-3 in blastoderm cells, fresh chBMC, and 40-day-cultured chBMC (Figure 2a). Isolated chBMC from eGFP $\mathrm{Tg}$ roosters were subjected to FACS using the stem cell surface-specific marker antibody SSEA-4. The results showed that $22.4 \%$ of cells expressed 


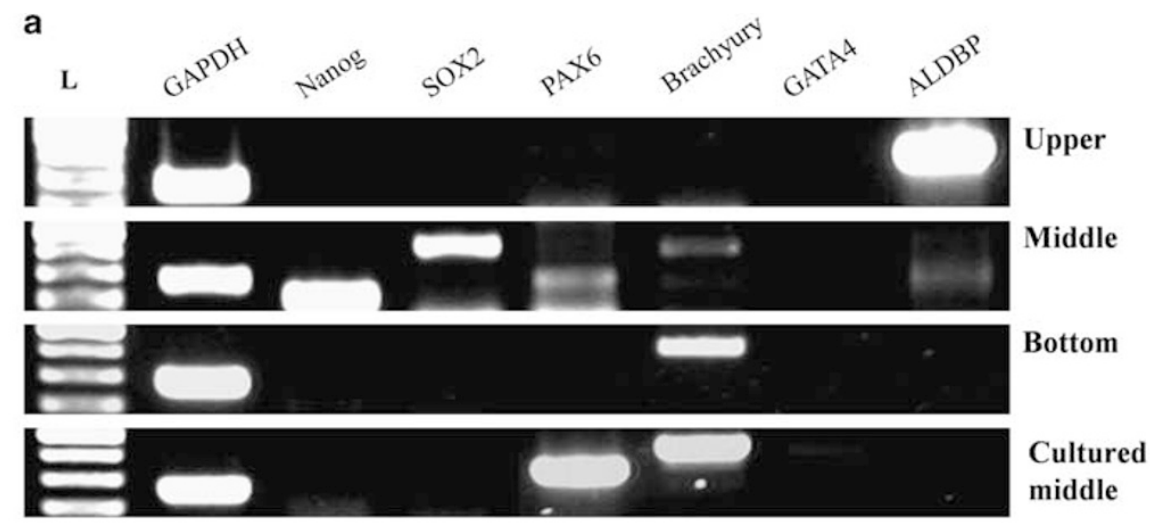

b

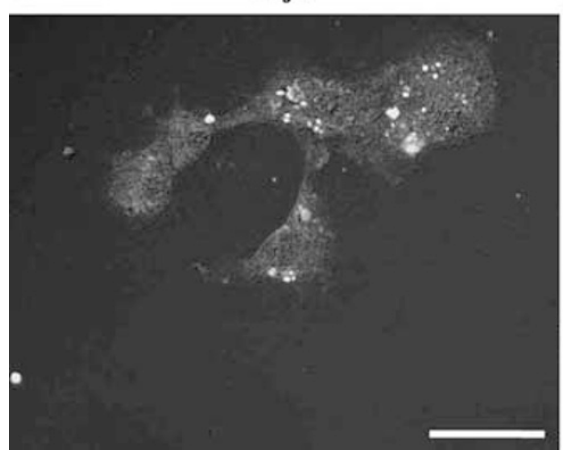

Brachyury

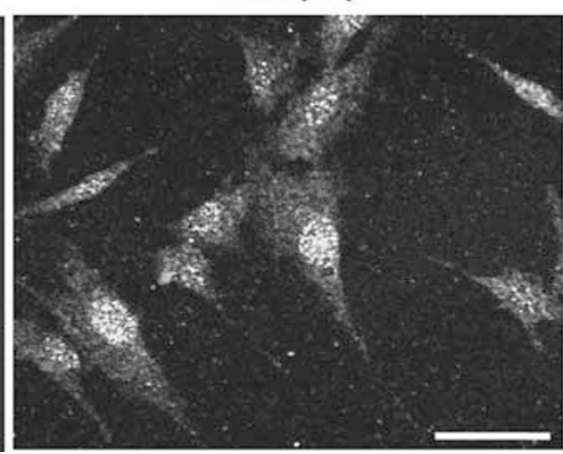

$\alpha$-fetoprotein

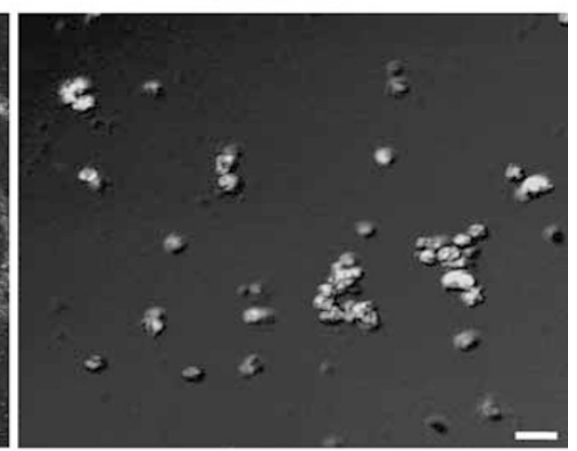

Figure 1 RT-PCR and immunocytochemical analysis of chBMC. (a) RNA was isolated from the upper, middle, and bottom-layered BMC populations separated by Percoll density gradient centrifugation. The upper-layered BMCs are largely fat and light cells, which expressed the ALDBP (adipocyte lipid droplet-binding protein) gene. BMC in the middle expressed stem cell-specific markers (Nanog, Sox2) and the bottom-layered BMC evidenced mesodermoriginated markers such as brachyury. Middle-layered BMC cultured for five passages without any cytokine or growth factors abrogated Nanog and Sox2 gene expression, and gained three germ-layered-specific marker genes (ectoderm: PAX6, mesoderm: Brachyury, endoderm: GATA4). (b) Isolated chBMC cultured for 10 days with LIF and bFGF supplement and sequentially cultured for 20 days without LIF and bFGF were reacted with three germline-specific antibodies (ectoderm: Tuj1, mesoderm: Brachury, endoderm: $\alpha$-fetoprotein). Scale bars: $20 \mu \mathrm{m}$.

GFP, $5.7 \%$ of cells were positive for SSEA-4, and only $0.4 \%$ of cells were positive for both GFP and SSEA-4 (Figure $2 \mathrm{~b}$ ).

In order to investigate the potential of chBMC for differentiation into male germ cells, the isolated cells were treated with $10^{-6} \mathrm{M}$ RA and evidenced a positive reaction against primordial germ cell (VASA) and male germ cell (C-kit, Dazl)-specific marker antibodies (Figure 3a). RT-PCR analysis showed that RA-treated chBMCs were positive for the meiotic (Dazl), and post-meiotic markers (C-kit and Stra 8). However, the non-RA-treated fresh chBMC did not express the aforementioned genes (Figure $3 \mathrm{~b}$ ). The expression of germ cell markers in human and mice BMCs was consistent with previous observations that also indicated that human mesenchymal stem cells spontaneously differentiated into germ cells in vitro. ${ }^{15}$

After busulfan treatment, number of cells in recipient's seminiferous tubles was reduced within 1 month (Figure $4 \mathrm{~b}$ ) and restored after 2 months (Figure 4c). The size of testis also decreased after 1 month due to affection of busulfan treatment (Figure $4 \mathrm{~d}$ ).

Due to the fact that the cells of EGFP Tg chickens express green fluorescence protein, BMCs from EGFP Tg chickens are a convenient material for determining their fate and localization. We sorted eGFP BMC, and then surgically transplanted them into the testes of the busulfan-treated recipient. Busulfan treatment induced chemical injury of spermatogenesis, resulting in reduction of cells number in chicken testes, which are located deep within the abdominal cavity. The localization and differentiation of donor eGFP BMCs in the recipient testes were evaluated using transversal sections of the recipients' testes. As is shown in Figure 5, eGFP BMC are scattered throughout the recipients' seminiferous tubules after 3 days of injection. Many tubules are ruptured as the result of the physical pressure inherent to injection (a). However, the GFP-positive cells were localized in the recipients' seminiferous tubules and evidenced extended occupation in the seminiferous tubules (10 days: (b); 20 days: (c); 40 days: (d) after GFP-positive donor cells injection). Confocal microscopy demonstrated the co-localization of eGFP-positive donor-derived BMCs with VASA, C-kit, and Dazl, which are germ-cell-specific markers in the recipients' testes (Figure 6).

Eight weeks later, spermatogenesis was completely recovered, the sperm quality parameters such as concentration, 
a
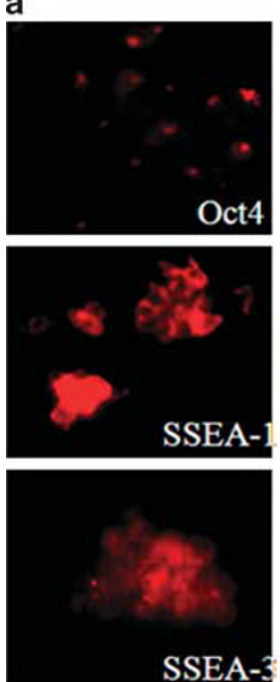

Blastoderm cell
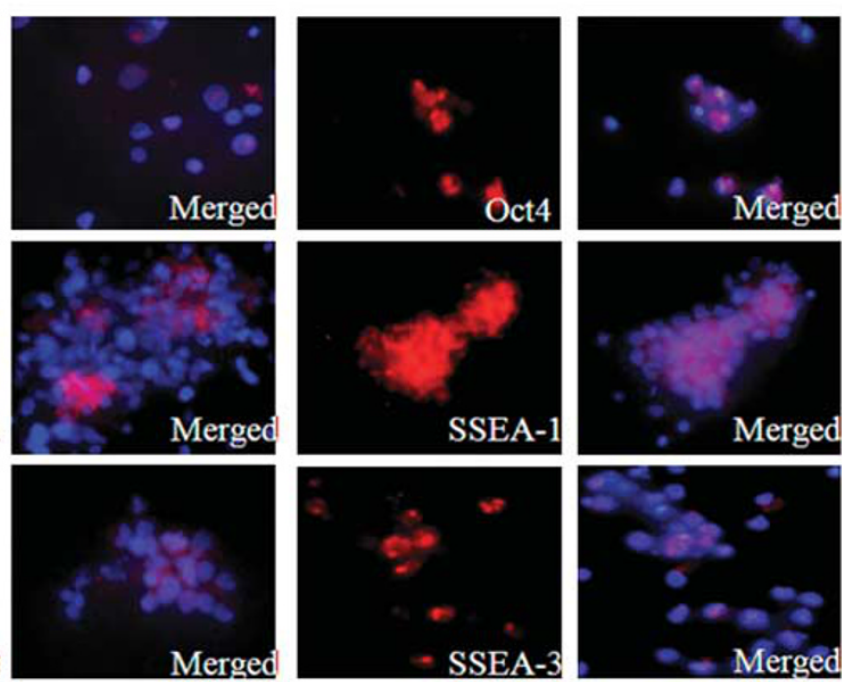

Fresh BMC

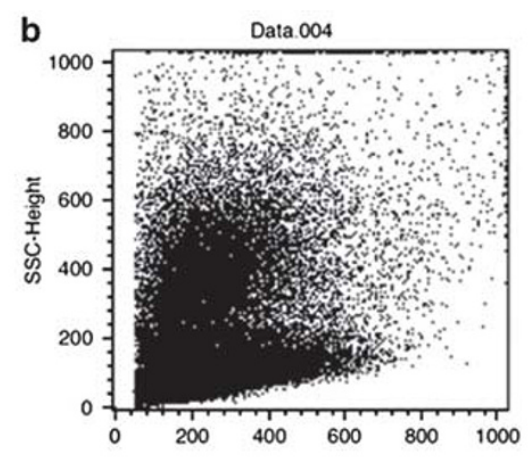

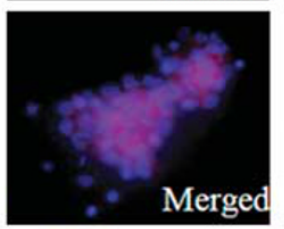
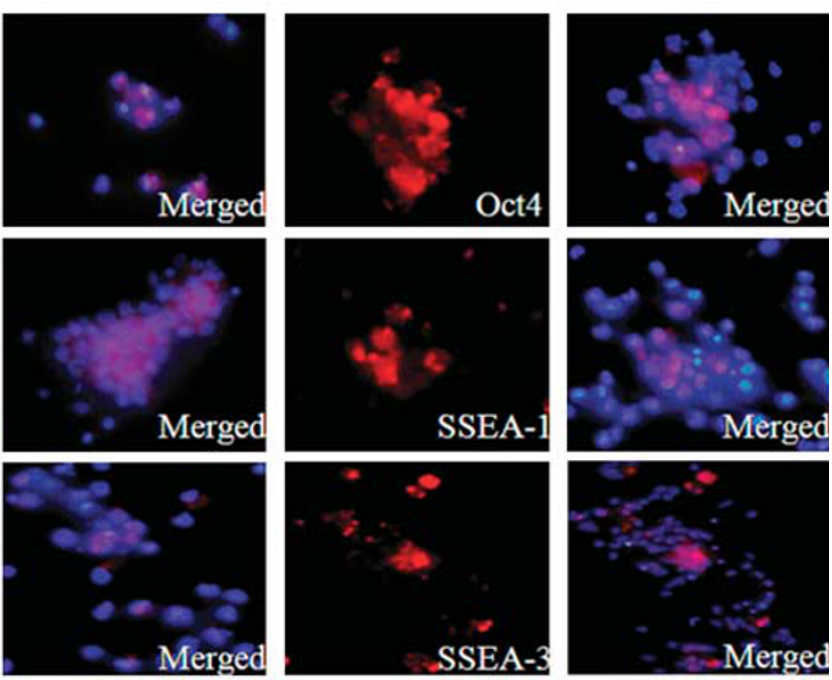

Cultured BMC

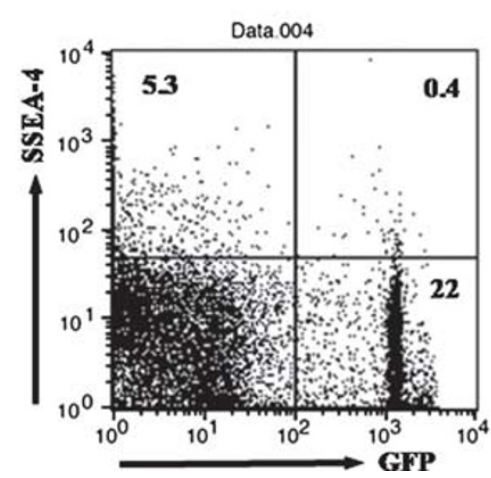

Figure 2 (a) Immunocytochemistry of blastoderm and bone marrow cells from normal chickens. Fluorescence images show stem cell-specific antibodies against Oct-4, SSEA-1 and SSEA-3 positive reacted cells (red, anti bodies) and the co-localization of positive antibody reactions with DAPI (purple, merged). Blastoderm cells corresponding to avian embryonic stem cells were utilized as a positive control. Fresh chBMC and 40-day-cultured chBMC were partially positive for immunoreactions with the antibodies. (b) FACS analysis of BMC isolated from eGFP Tg roosters. In all, $22 \%$ of cells isolated from bone marrow were eGFP positive, $5.7 \%$ of cells were SSEA-4 positive, and $0.4 \%$ of cells were both eGFP and SSEA-4 positive. The color reproduction of this figure is available on the html full text version of the manuscript.

volume, viability, total sperm numbers, and fertilization rate of ejaculated spermatozoa from recipients were assessed and the results were shown in Table 2. The semen of the BMCtransferred recipients was inferior in all aspects of the parameters (Table 2).

Using the primer sets for the $e G F P$ and $n e o^{R}$ genes in the retroviral vector used in the production of eGFP Tg chickens ${ }^{18}$ (Figure 7a), we attempted to detect spermatozoa differentiated from donor eGFP BMCs in the recipient semen. PCR analysis demonstrated the integration of the eGFP and $n e o^{R}$ genes in the genomic DNA of recipients' sperm (Figure $7 b$ ). To investigate ratio of eGFP-positive spermatozoa in ejaculated sperm, semen samples from normal rooster, BMCtransferred recipient and eGFP $\mathrm{Tg}$ rooster were conducted to immunocytochemistry analysis. Results indicated that eGFPpositive spermatozoa were not observed in normal rooster and $100 \%$ of spermatozoa from eGFP Tg rooster positively react with GFP-specific antibody (Figure 7c). Four eGFP- positive germline chimera recipients based on PCR analysis showed that frequencies of eGFP-positive spermatozoa in ejaculated sperm are between 0.01 and $0.82 \%$ individually (Table 2; Figure 7d).

Among 13 recipients of BMC transplantation, 4 recipients were killed for the tracing of the localization and differentiation of donor eGFP BMCs in the recipient testis. In the rest of them, the transdifferentiation of BMC into male germ cells based on PCR analysis was confirmed in five recipients, and two recipients produced three eGFP-positive chicks out of a total of 379 offspring (Table 3; Figure 7e). As summarized in Table 3, we prepared BMC from 8-week-old or 30week-old eGFP donors and transplanted them into recipients $(8,16$, and 40 weeks old). One of the two recipients that had undergone BMC transplantation at too early an age (8 weeks old) were dead or unable to produce semen after donor cell transplantation, and regression of testes was noted in another recipient at 5 months after surgery. Two recipients received 
a
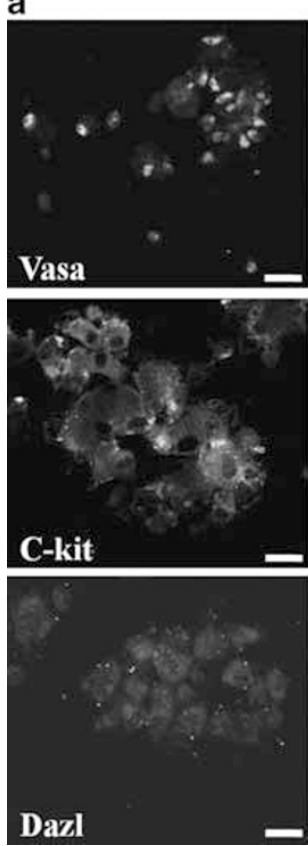
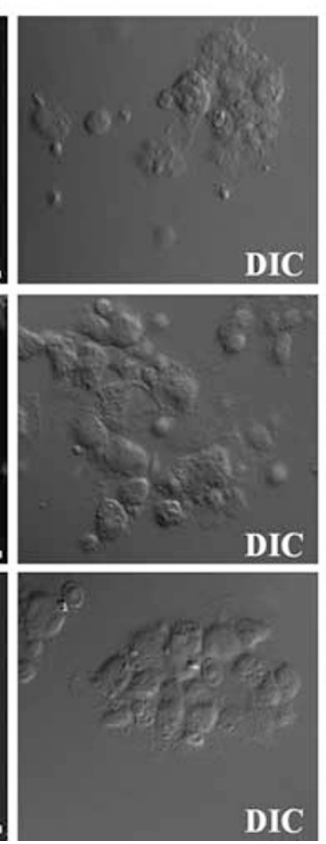
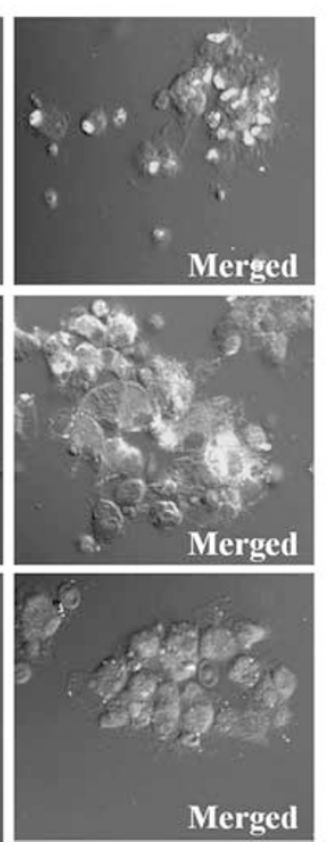

b

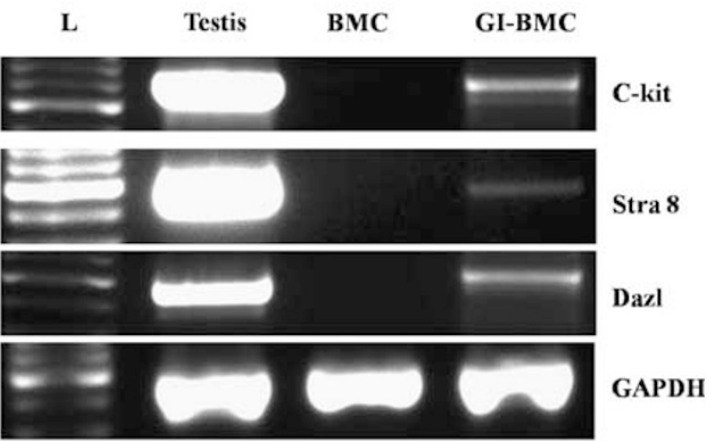

Figure 3 Immunocytochemistry and RT-PCR analysis of chBMC after 15 days of RA treatment. (a) Confocal images show germ-cell-specific antibodies against Vasa, C-kit and Dazl, positively reacting cells (name of antibody, green), DIC, and co-localization of positive antibody reactions with optical images (merged). (b) RNA was isolated from adult wild-type testis, from fresh BMC and from germ cell differentiation induced bone marrow cells (GI-BMC) and processed for RT-PCR analysis. GAPDH was used as a control. Scale bars: $20 \mu \mathrm{m}$.

a

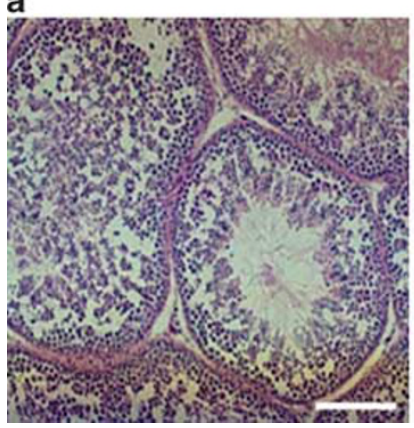

b

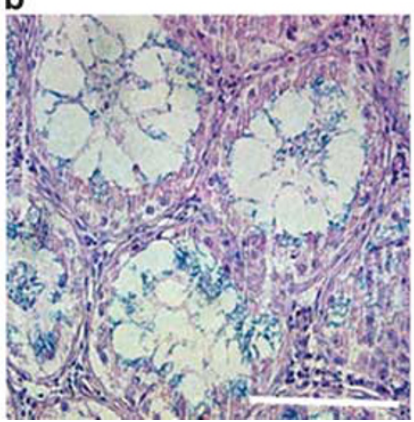

c

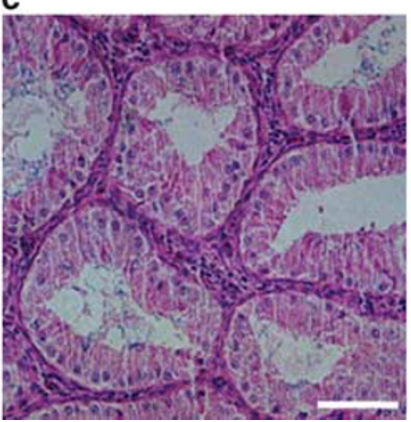

d

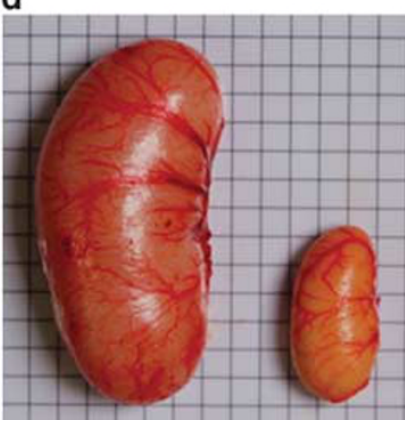

Figure 4 Photomicrograph of a cross-section of a testis of busulfan-treated roosters. (a) Seminiferous tubule of normal rooster. (b) Seminiferous tubule of rooster 1 month after busulfan treatment. (c) Seminiferous tubule of rooster 2 month after busulfan treatment. (d) Size comparison of normal (left, $2.6 \mathrm{~cm}$ ) and busulfan treated (right, $1.3 \mathrm{~cm}$ ) testes. Scale bars: $50 \mu \mathrm{m}$.

eGFP BMC at the age of 16 weeks, and four out of five recipients who received eGFP BMC from the age of 30 weeks were observed to produce sperm. One of the two recipients who received eGFP BMC from the age of 16 weeks and three of four recipients who received eGFP BMC from the age of 30 weeks evidenced eGFP-positive testicular cells derived from transplanted BMCs. Among the four recipients that produced eGFP gene-integrated sperm, two recipients generated eGFP-positive progenies $(2 / 104 ; 1.9 \%$ and $1 / 92$; $1.1 \%$ ) as the result of testcrossing with non-Tg hens (Table 3; Figure 7).

To confirm whether eGFP-positive progeny derived from injected eGFP BMC or not, we compared chromosomal location of the transgene in donor eGFP BMC and progeny. The replication defective retrovirus that contain eGFP gene inserted between the nucleotides of $55890-55891$ on chromosome 26 of eGFP $\mathrm{Tg}$ chicken. ${ }^{17}$ Sequencing result indicated that genomic regions flanking the provirus of donor cell and eGFP progeny are 100\% matched (Figure 8).

\section{DISCUSSION}

The principal objectives of this study were to demonstrate the pluripotency and transdifferentiation ability of chicken BMC, and the successful generation of BMC-mediated germline chimeric chickens. Several methods can be used to isolate BMC, including simple flushing, Ficoll hypaque gradient, and 
a

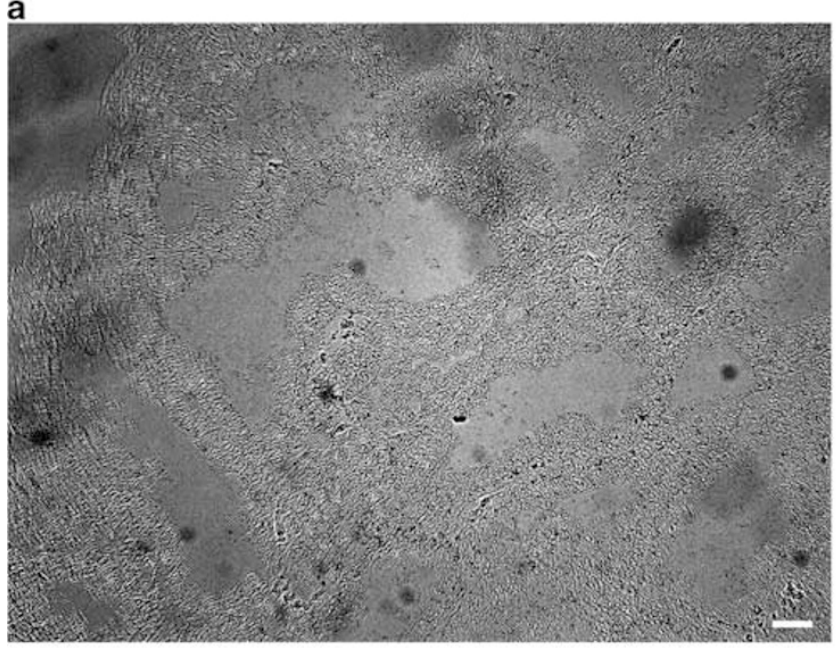

c

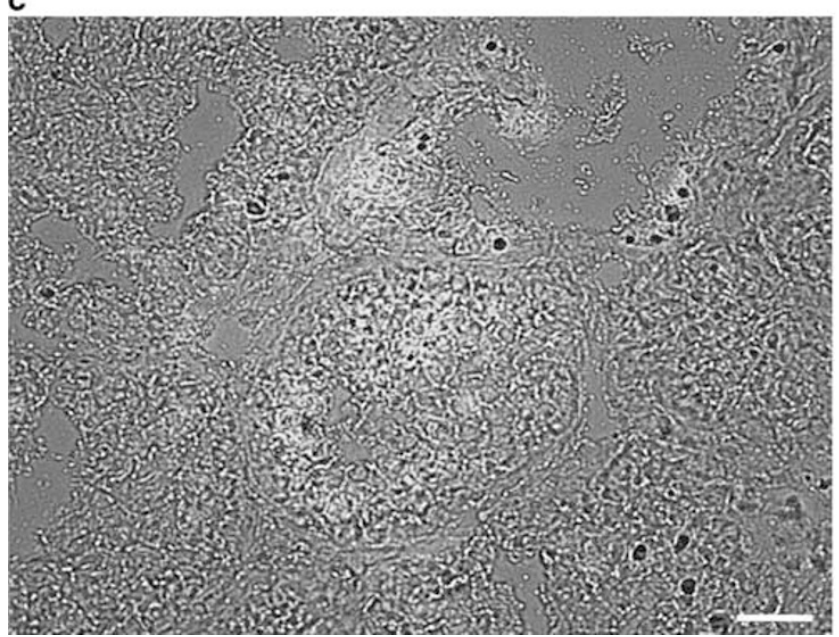

b

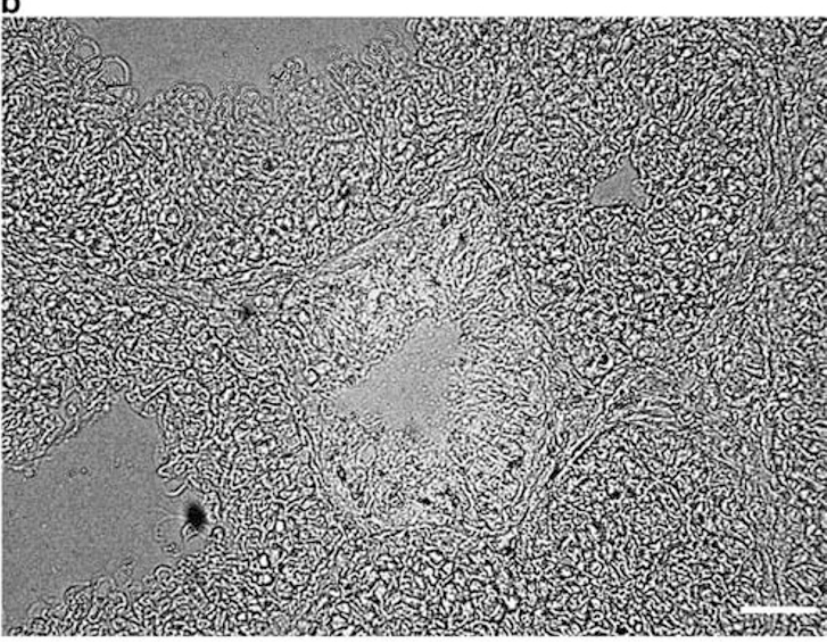

d

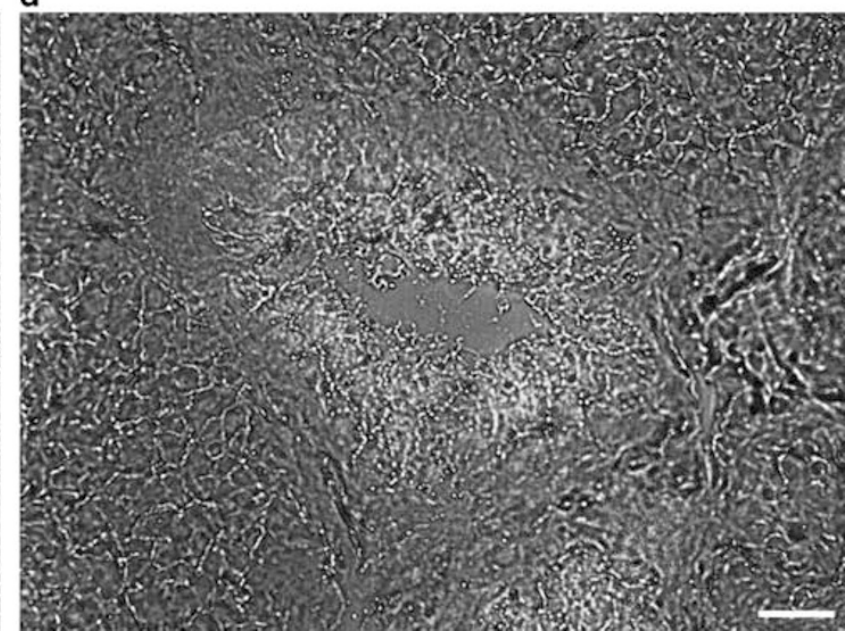

Figure 5 Localization of ChGFP BMC in the recipient's seminiferous tubules. Confocal images show eGFP BMCs scattered in the recipient's seminiferous tubules after 3 days of eGFP BMC injections. Many tubules are ruptured as the result of physical pressure during injection (a). After 10, 20, and 40 days of eGFP BMC injection, GFP-positive cells are localized in the recipient's seminiferous tubules. Transplanted donor cells are divided and evidence extended occupation time in the seminiferous tubules (b: 10 days, c: 20 days, d: 40 days after GFP-positive donor cells injection). Scale bars: $20 \mu \mathrm{m}$.

adherent cell collection. ${ }^{13-15}$ The donor cells employed in this study were isolated using Percoll density gradients and FACS from eGFP Tg roosters. We roughly separated the cell population with multipotency, and then consequentially sorted GFP cells that positively reacted with SSEA-4. Thus, as compared with other methods, our BMC isolation method is far more accurate and requires less time.

In mammals, a number of reports have demonstrated that BMC included a variety of cell types, including mesenchymal stem cells, hematopoietic stem cells, immune-related cells, osteoblasts, adipocytes, ESCs, and unknown multipotent adult progenitor cells. ${ }^{6,22,23}$ Mammalian BMC can differentiate into a variety of cell types, including adipocytes, endothelial cells, epithelial cells, glial cells, hepatocytes, neurons, cardiac muscle cells, skeletal muscle cells, and smooth muscle cells. ${ }^{24-26}$ It has been suggested that BMC can differentiate into a variety of cell types originating from all three germ layers. Among these differentiation capabilities, the generation of germ cells from BMC is one of their most interesting characteristics. Recently, Johnson et al ${ }^{13,27,28}$ reported that mammalian ovaries possessed persistently large germline stem cells and enabled follicular renewal in mammalian females. In addition, it has been documented previously that mammalian oocytes originated from putative germ cells in $\mathrm{BM}$ and were distributed to the ovaries by the peripheral blood. ${ }^{29}$ Although the issue of spermatogenesis from BMC is somewhat controversial, several previous reports have discovered evidence that BMC can transdifferentiate into male germ cells. ${ }^{30}$ Nayernia et $a l^{14,15}$ demonstrated for the first time that ESC-derived germ cells were able to generate offspring mice, and also showed that murine BMC could differentiate into male germ cells. Recently, Lue and co-workers ${ }^{15,23,31}$ reported that BMC transplanted into the testes of a busulfan-treated infertility mouse model 

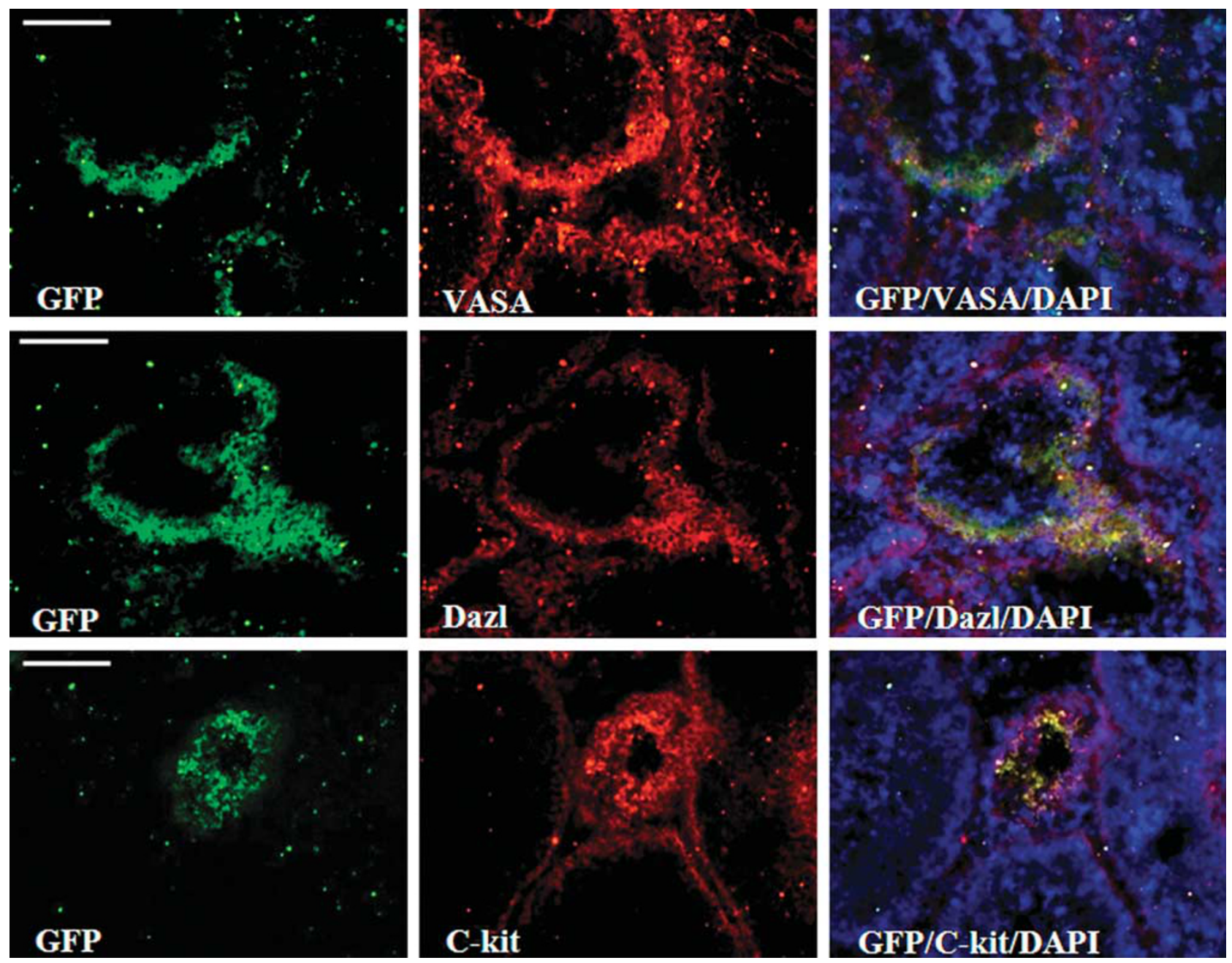

Figure 6 Immunocytochemistry of GFP-positive BMC in recipient's seminiferous tubules. Transverse sections of recipient's testes after 40 days after donor cell injection conducted via cryostat method. Fluorescent images show GFP-positive donor cells (green) and germ-cell-specific antibodies against Vasa, C-kit, and Dazl positively reacting cells (name of antibody, red), co-localization of GFP and positive antibody reactions (GFP + name of antibody) and co-localization of GFP, positive antibody reactions and optical images of cells (GFP + name of antibody + DIC). Scale bars: $50 \mu \mathrm{m}$.. The color reproduction of this figure is available on the html full text version of the manuscript.

Table 2 Semen analysis of eGFP BMCs-transferred recipients

\begin{tabular}{|c|c|c|c|c|c|}
\hline Parameters & Normal & KU-16 & $\mathrm{KU}-17$ & KU-18 & KU-19 \\
\hline Sperm concentration $\left(10^{8} / \mathrm{ml}\right)$ & $207 \pm 32^{\mathrm{a}}$ & $7.1 \pm 0.9^{c}$ & $4.2 \pm 1.7^{c}$ & $91 \pm 15^{\mathrm{b}}$ & $102 \pm 11^{b}$ \\
\hline Viability (\%) & $85 \pm 6^{\mathrm{a}}$ & $39 \pm 6^{b}$ & $44 \pm 6^{b}$ & $35 \pm 5^{c}$ & $52 \pm 8^{b}$ \\
\hline Total sperm number ( $10^{8} /$ ejaculate) & $72.45 \pm 2.88^{\mathrm{a}}$ & $1.15 \pm 0.025^{c}$ & $0.6 \pm 0.04^{c}$ & $19.2 \pm 0.58^{b}$ & $19.4 \pm 0.44^{b}$ \\
\hline$\%$ of eGFP-positive ${ }^{a}$ sperm & 0 & 0.69 & 0.82 & 0.08 & 0.01 \\
\hline
\end{tabular}

a Detection of eGFP-positive spermatozoa was done by immunocytochemistry analysis of ejaculated frozen semen.

a,b,c Statistical analyses were carried out by Student's $t$-test, and means with different superscripts within the same columns were significantly different $(P<0.05)$.

appeared to differentiate into germ cells, Sertoli cells, and Leydig cells. Moreover, Hua et $\mathrm{al}^{16}$ reported that human fetal BMC differentiates into spermatids. This finding raises the possibility that BMC might be utilized in the treatment of male infertility and testosterone deficiency. ${ }^{32}$ According to our results, avian BMC also react positively with three germlayered-specific marker antibodies after the induction of random differentiation (Figure 1). 
a

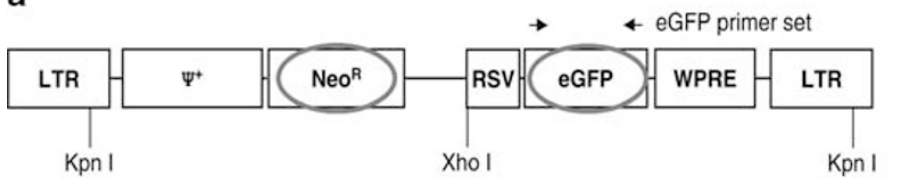

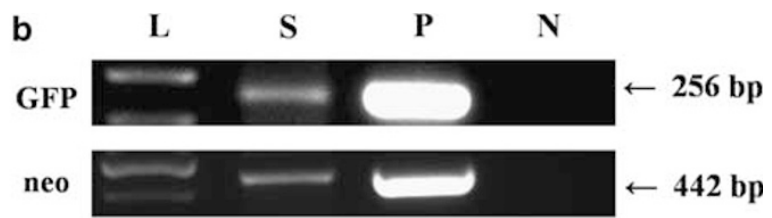

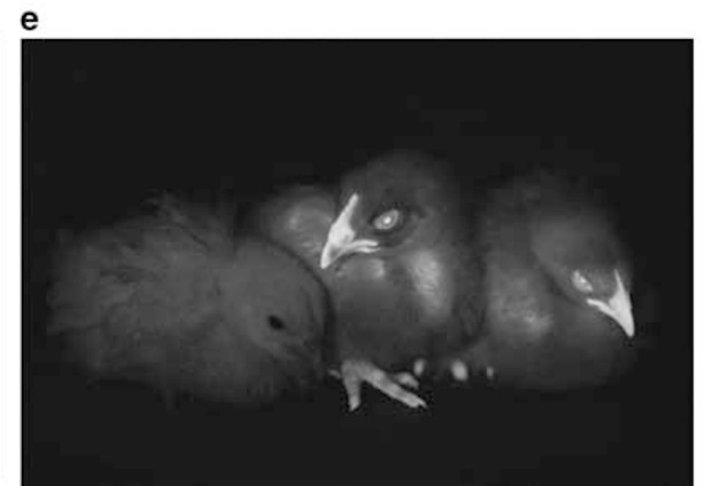

C

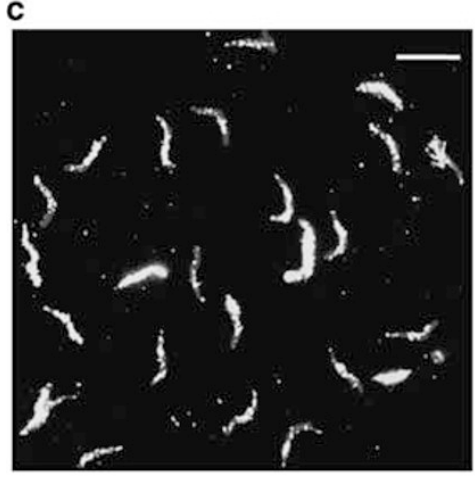

d

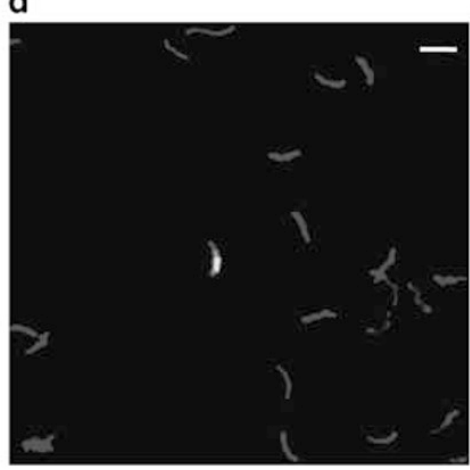

Figure 7 (a) Structure of retroviral vector used to generate the eGFP $\mathrm{Tg}$ chicken. $\mathrm{Neo}^{\mathrm{R}}$ and eGFP genes detectable specific primers were designed. (b) Amplified PCR bands. L, 100 bp molecular ladder; S, recipient's sperm genomic DNA; P, positive control with sperm genomic DNA from eGFP Tg rooster; $\mathrm{N}$, negative control with sperm genomic DNA from normal roosters. $\mathrm{NeO}^{\mathrm{R}}$ and eGFP genes were detected in recipient's sperm genomic DNA.

(c) Immunocytochemistry of GFP-positive spermatozoa in semen of eGFP Tg rooster (c) and eGFP BMC-transferred recipient (d). Fluorescence image shows DAPI-stained GFP-negative sperm head (blue) and GFP-positive sperm head (green, arrowed). Scale bars: $20 \mu \mathrm{m}$. (e) eGFP chicks generated from transdifferentiated eGFP BMC at 6 weeks of age. chBMC were obtained from 30-week-old eGFP Tg roosters and eGFP chicks hatched after artificial insemination administered to normal hens. The first bird on the left is a non-transgenic control chick.

Table 3 Germline chimera production by transfer of GFP BMC into the testes of normal recipients

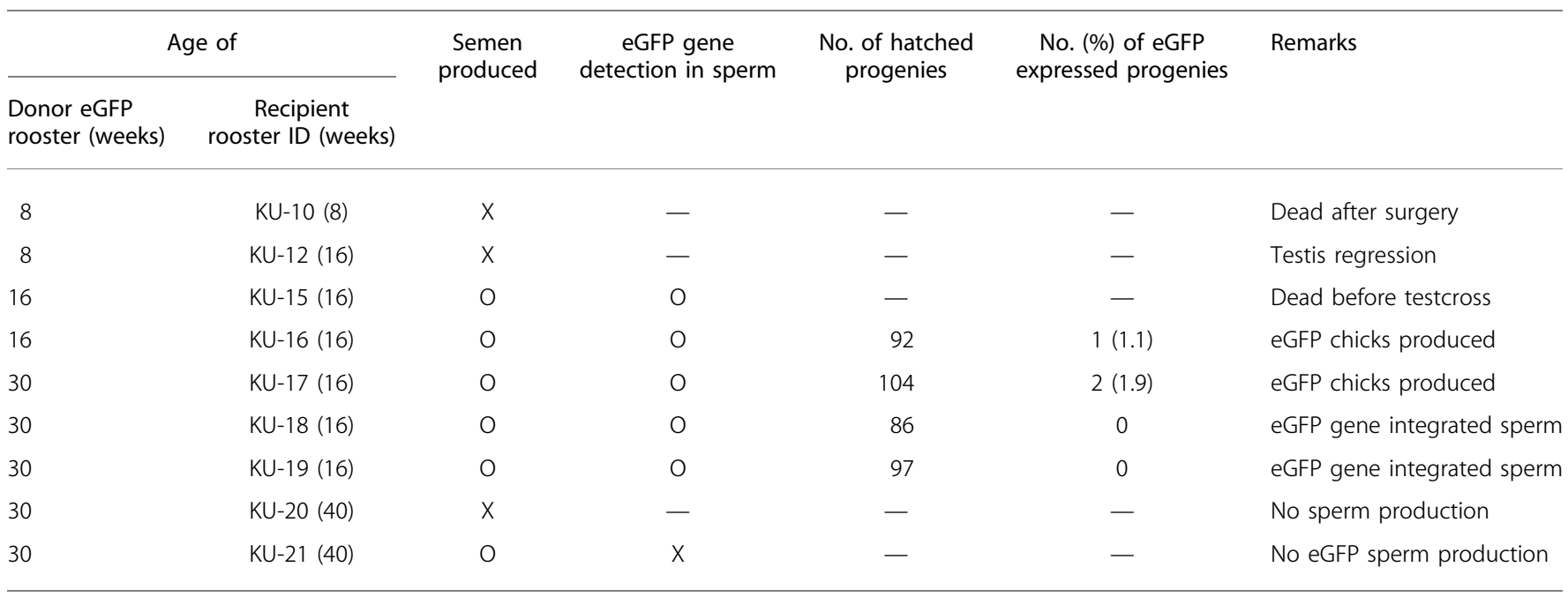

$O$, positive; $X$, negative.

The molecular mechanism underlying adult stem cell plasticity and the targeting of BMC differentiation toward germ cells remain unclear. ${ }^{33}$ The testes represent a unique microenvironment for donor stem cell migration, proliferation, differentiation, and apoptosis. The testes are protected from immunological influences by the blood-testis barrier, thereby allowing the recipient to host donor cells without rejection. These characteristics of the testes render the study of adult stem cells quite difficult. ${ }^{31}$
In immunocytochemical analysis, we utilized blastoderm cells (avian embryonic stem cell) as positive controls. Fresh and 40-day-cultured BMC and blastoderm cells were observed to partially react with murine immune markers such as Oct-4, SSEA- 1 and SSEA-3, which evidence minimal crossactivity with chickens. The results demonstrated that $22 \%$ of the cells were positive for GFP, $5.7 \%$ of cells reacted positively with the stem cell surface marker SSEA-4, and only $0.4 \%$ of the cells were positive for both GFP and SSEA-4 (Figure 2b). 


\begin{tabular}{|l|l|}
\hline 3' LTR & 5'LTR \\
\hline
\end{tabular}

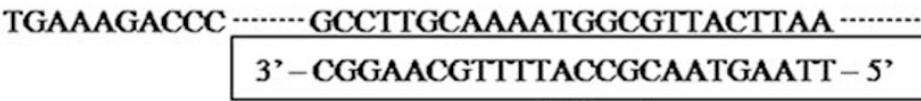

$\leftarrow$ Cf- R primer

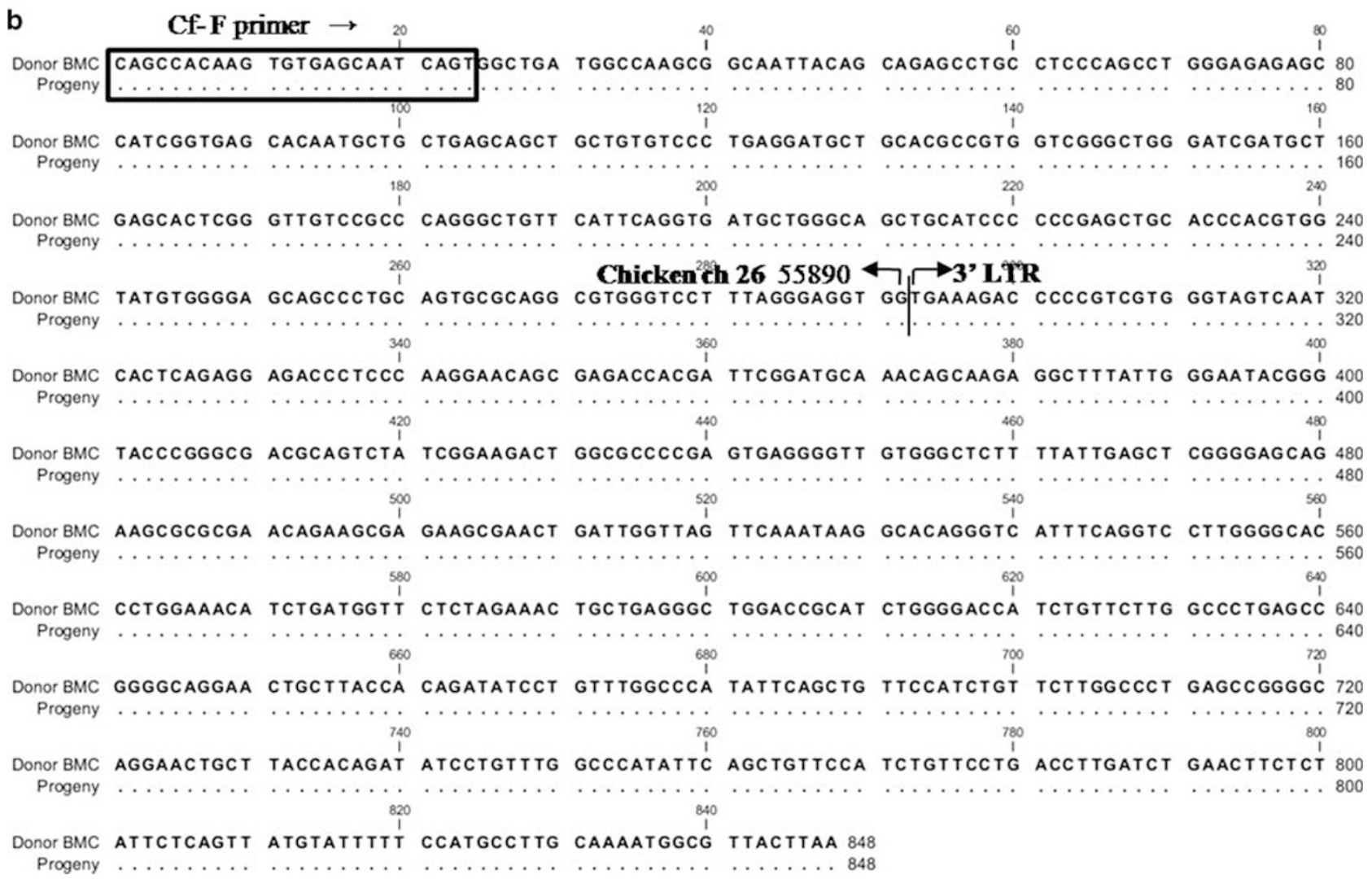

Figure 8 (a) Previous analysis revealed that LNRGW provirus is inserted between the nucleotides of 55 890-55 891 on chicken chromosome 26 . The nucleotide sequence numbers of chicken chromosome 26 are indicated on the top of some bases. (b) Comparison of nucleotide sequences flanking LNRGW provirus from donor cell and progeny. Primers are indicated by boxed area.

As compared with the former results from mammals, the ranges of GFP-positive cells and stem cell-specific markerpositive cells in BMCs from GFP Tg animals were 11-50\% depending on the individual. ${ }^{15,34}$ The lower levels of positive cells with stem cell-specific markers may be attributable to the minimal cross-activity of antibodies. For this reason, the immunological markers for characterizing chicken adult stem cells, including BMC and germ cells, requires more development. Nevertheless, our results showed the reaction of these mammalian Abs with chicken adult stem cells.
It has been well established that RA is deeply involved in the regulation of testicular function. An excess or deficiency of vitamin A can result in spermatogenetic disorders or the cessation of spermatogenesis. Previous studies have shown that BMC are able to transdifferentiate into male germ cells by RA in rodents and humans. ${ }^{15,16}$ However, RA has many other functions, including developmental regulation and the differentiation of neural cells and cardiac cells. The relevant mechanism and appropriate concentrations of RA for germ cell differentiation have yet to be clearly elucidated. In a 
recent study, it was suggested that the testicular environment may control and support the differentiation of BMC into somatic and germ cells. ${ }^{32}$ In our study, avian BMC can be differentiated into germ cells in vitro by RA treatment and in the seminiferous tubules of the recipient. Therefore, this finding indicates that avian BMC may have characteristics similar to rodent BMCs.

OCT4 and Nanog are transcription factors that may regulate pluripotency and are detected in both pluripotent cells and early germ cells. ${ }^{35}$ Levels of VASA (Cvh: chicken VASA homologue) are increased in germ cells such as PGC from the late migration stage to the post-meiotic stage. ${ }^{36}$ PGC and spermatogonial cells express the cytokine receptor c-kit at relatively high levels. DAZL is a germ-cell-specific protein for gametogenesis and a candidate causal factor of azoospermia factor $c$, a common genetic cause of male infertility. In the present study, we noted that avian BMC could also differentiate into male germ cells after RA treatment in vitro (Figure 3 ) and in the recipient's seminiferous tubules in vitro (Figure 6). Interestingly, these results are consistent with former reported results with mammalian BMCs. ${ }^{14-16,32,37}$ Furthermore, 40 days after the transfer of eGFP chBMCs into recipients' testes, GFP donor cells were detected in the seminiferous tubules and some of the spermatozoa of the recipients were confirmed carry the eGFP and neo ${ }^{\mathrm{R}}$ marker genes (Figure $7 \mathrm{a}$ and $\mathrm{b}$ ).

The ideal treatment for recipient with busulfan has been used for the induction of complete infertility. But, the optimal dose of busulfan has been not clearly identified in chicken and we lost half of prepared recipients before BMC transfer due to lethality of high dose of busulfan. Thus, in this study, we treated busulfan with low dosage and lead reduction of cell number in seminiferous tubules of recipient (Figure 4). Less number of cells in recipient's seminiferous tubules might be more favorable to the settlement of donor cells in tissue of recipients.

Qualities of collected semen from recipients for artificial insemination purpose was analyzed. Results showed that concentrations, volumes, viabilities, total ejaculated sperm numbers and fertilization rates of eGFP BMCs-transferred recipients were significantly lower than those of normal rooster (Table 2). As seen in Figures $4 \mathrm{~b}$ and $5 \mathrm{a}$, busulfan treatment reduced cell number in seminiferous tubules and donor cell transfer procedure induced rupture of seminiferous tubules. Thus, in our opinion, busulfan treatment and cell transfer procedure may be explainable major reasons for low quality of semen from recipients. At the beginning we tried to detect GFP-positive spermatozoa through fluorescence microscope but failed, presumably due to low expression of the GFP gene under CMV promoter and/or existence of a limited amount of protein in spermatozoa. ${ }^{17}$ Alternatively, however, immunocytochemical trial was successful and we could detect GFP-positive spermatozoa (Figure 7c and d). As expected, no eGFP-positive spermatozoa were observed in normal rooster, while $100 \%$ of spermatozoa from
eGFP Tg rooster positively reacted with GFP-specific antibody (Figure 7c). Four eGFP-positive germline chimera recipients based on PCR analysis showed that frequencies of eGFP-positive spermatozoa in ejaculated sperm are between 0.01 and $0.82 \%$ individually (Table 2; Figure $7 \mathrm{~d}$ ). Therefore, in our opinion, no positive progenies out of the recipients due to very low rate of GFP-positive spermatozoa in ejaculated semen. This result may suggest that very limited cells from transferred donor cells are differentiated into germ cells.

EGFP chBMC transferred into the testes of nine recipients resulted in the production of three eGFP chicks derived from donor cells. Only five of the nine recipients produced spermatozoa harboring the eGFP marker gene, and two of the five recipients produced three eGFP chicks (Table 3 ).

To investigate Genomic regions flanking the provirus of donor cell and eGFP progeny were analyzed by sequencing and result indicated that sequences of donor cell and progeny are 100\% matched (Figure 8). Thus, this result suggests that eGFP-positive progenies are not derived from host germ cells that are infected by shedded virus from donor eGFP BMC. As compared with recent reports, even considering the broad variances in other germline chimera chicken production methods, our efficiency was generally lower than other methods (testicular cell transfer $(\sim 2 \%)$, PGC transfer $(0.6-$ $49 \%)$ and chicken embryonic stem cell transfer $(\sim 20$ $70 \%))^{4,38,39}$ Although our current research showed low frequency of eGFP-expressed progenies, we would like to emphasize that our study offered the first successful case of BMCs-derived progenies. Therefore, our results suggest that BMC could be a tool for the production of germline chimeras, and for germ cell development study.

In conclusion, our results first demonstrated that chBMCs are multipotent and capable of differentiating into male germ cells. We obtained three progenies from the chBMC-derived spermatocytes. Thus, this study, validated for the first time in avian species, offers valuable information for future avian adult stem cell research. In addition, the success of BMC transplantation may suggest a variety of novel application areas, including the preservation of the reproductive potential of genetically valuable individuals and the production of Tg sperm via genetic manipulation.

\section{DISCLOSURE/CONFLICT OF INTEREST}

The authors declare no conflict of interest.

1. Lillico SG, McGrew MJ, Sherman A, et al. Transgenic chickens as bioreactors for protein-based drugs. Drug Discov Today 2005;10: 191-196.

2. Park TS, Jeong DK, Kim JN, et al. Improved germline transmission in chicken chimeras produced by transplantation of gonadal primordial germ cells into recipient embryos. Biol Reprod 2003;68: 1657-1662.

3. Etches RJ, Clark ME, Toner A, et al. Contributions to somatic and germline lineages of chicken blastodermal cells maintained in culture. Mol Reprod Dev 1996;45:291-298.

4. Lee YM, Jung JG, Kim JN, et al. A testis-mediated germline chimera production based on transfer of chicken testicular cells directly into heterologous testes. Biol Reprod 2006;75:380-386. 
5. Yasuo I, Mikawa T. Somatic transgenesis in the avian model system. Birth Defects Res 2005;75:19-27.

6. Grove JE, Bruscia E, Krause DS. Plasticity of bone marrow-derived stem cells. Stem Cells 2004;22:487-500.

7. Petersen $\mathrm{BE}$, Bowen $\mathrm{WC}$, Patrene $\mathrm{KD}$, et al. Bone marrow as a potential source of hepatic oval cells. Science 1999;284:1168-1170.

8. Ferrari G, Cusella-DeAngelis G, Coletta M, et al. Muscle regeneration by marrow-derived myogenic precursors. Science 1998;279:1528-1530.

9. Mezey E, Chandross KJ, Harta G, et al. Turning blood into brain: cells bearing neuronal antigens generated in vivo from bone marrow. Science 2000;290:1779-1782.

10. Brazelton TR, Rossi FM, Keshet $\mathrm{Gl}$, et al. From marrow to brain: expression of neuronal phenotypes in adult mice. Science 2000;290:1775-1779.

11. Orlic D, Kajstura J, Chimenti S, et al. Bone marrow cells regenerate infarcted myocardium. Nature 2001;410:701-705.

12. Ainsworth C. Bone cells linked to creation of fresh eggs in mammals. Nature 2005:436:609.

13. Lee $\mathrm{HJ}$, Selesniemi $\mathrm{K}$, Niikura $\mathrm{Y}$, et al. Bone marrow transplantation generates immature oocytes and rescues long-term fertility in a preclinical mouse model of chemotherapy-induced premature ovarian failure. J Clin Oncol 2007;25:3198-3204.

14. Drusenheimer N, Wulf G, Nolte J, et al. Putative human male germ cells from bone marrow stem cells. Soc Reprod Fertil Suppl 2007;63: 69-76.

15. Nayernia $\mathrm{K}$, Lee $\mathrm{JH}$, Drusenheimer $\mathrm{N}$, et al. Derivation of male germ cells from bone marrow stem cells. Lab Invest 2006;86:654-663.

16. Hua J, Pan S, Yang C, et al. Derivation of male germ cell-like lineage from human fetal bone marrow stem cells. Reprod Biomed Online 2009;19:99-105.

17. Koo BC, Kwon MS, Choi BR, et al. Production of germline transgenic chickens expressing enhanced green fluorescent protein using a MoMLV-based retrovirus vector. FASEB J 2006;20:2251-2260.

18. Kwon MS, Koo BC, Choi BR, et al. Development of transgenic chickens expressing enhanced green fluorescent protein. Biochem Biophys Res Commun 2004;320:442-448.

19. Oulad-Abdelghani $M$, Bouillet $P$, Decimo $D$, et al. Characterization of a premeiotic germ cell-specific cytoplasmic protein encoded by Stra8, a novel retinoic acid-responsive gene. J Cell Biol 1996;135: 469-477.

20. Burrows WH, Quinn JP. Collection of spermatozoa from domestic chicken and turkey. Poult Sci 1937;16:19-24.

21. Chenna R, Sugawara $H$, Koike $T$, et al. Multiple sequence alignment with the Clustal series of programs. Nucleic Acids Res 2003;31: 3497-3500.

22. Srour EF, Jetmore A, Wolber FM, et al. Homing, cell cycle kinetics and fate of transplanted hematopoietic stem cells. Leukemia 2001;15:1681-1684.

23. Sottile V. Bone marrow as a source of stem cells and germ cells? Perspect Transplant Cell Tissue Res 2007;328:1-5.
24. Kolf CM, Cho E, Tuan RS. Mesenchymal stromal cells. Biology of adult mesenchymal stem cells: regulation of niche, selfrenewal and differentiation. Arthritis Res Ther 2007;9:204.

25. Phinney DG, Prockop DJ. Concise review: mesenchymal stem/ multipotent stromal cells: the state of transdifferentiation and modes of tissue repair-current views. Stem Cells 2007;25:2896-2902.

26. Satija NK, Gurudutta GU, Sharma S, et al. Mesenchymal stem cells: molecular targets for tissue engineering. Stem Cells Dev 2007;16:7-23.

27. Johnson J, Bagley J, Skaznik-Wikiel M, et al. Oocyte generation in adult mammalian ovaries by putative germ cells in bone marrow and peripheral blood. Cell 2005;122:303-315.

28. Bukovsky A, Ayala ME, Dominguez $\mathrm{R}$, et al. Bone marrow derived cells and alternative pathways of oogenesis in adult rodents. Cell Cycle 2007;6:2306-2309.

29. Johnson J, Canning J, Kaneko T, et al. Germline stem cells and follicular renewal in the postnatal mammalian ovary. Nature 2004;428: 145-150.

30. Horn MM, Paz AH, Duarte ME, et al. Germinative testicular cells and bone marrow mononuclear cells transplanted to a rat model of testicular degeneration. Cloning Stem Cells 2008;10:543-546.

31. Yazawa T, Mizutani T, Yamada K, et al. Differentiation of adult stem cells derived from bone marrow stroma into Leydig or adrenocortical cells. Endocrinology 2006;147:4104-4111.

32. Lue Y, Erkkila K, Liu PY, et al. Fate of bone marrow stem cells transplanted into the testis: potential implication for men with testicular failure. Am J Pathol 2007;170:899-908.

33. Lin CS, Xin ZC, Deng CH, et al. Recent advances in andrology-related stem cell research. Asian J Androl 2008;10:171-175.

34. Harting MT, Jimenez F, Cox CS. Isolation of mesenchymal stem cells (MSC) from green fluorescent protein positive (GFP+) transgenic rodents: the grass is not always green(er). Stem Cells Dev 2008;18: 127-136.

35. Nagano MC. In vitro gamete derivation from pluripotent stem cells: progress and perspective. Biol Reprod 2007;76:546-551.

36. Toyooka Y, Tsunekawa N, Akasu R, et al. Embryonic stem cells can form germ cells in vitro. Proc Natl Acad Sci USA 2003;100:11457-11462.

37. Ogawa T, Dobrinski I, Mary RA, et al. Transplantation of male germ line stem cells restores fertility in infertile mice. Nat Med 2000;6:29-34.

38. Han JY. Germ cells and transgenesis in chickens. Comp Immunol Microbiol Infect Dis 2009;32:61-80.

39. van de Lavoir MC, Mather-Love C, Leighton $\mathrm{P}$, et al. High-grade transgenic somatic chimeras from chicken embryonic stem cells. Mech Dev 2006;123:31-41.

This work is licensed under the Creative Commons Attribution-NonCommercial-Share Alike

3.0 Unported License. To view a copy of this license, visit http://creativecommons.org/licenses/by-nc-sa/3.0/ 